\title{
Article
}

\section{The prevalence and impact of child maltreatment and other types of victimization in the UK: Findings from a population survey of caregivers, children and young people and young adults}

Radford, Lorraine, Corral, Susana, Bradley, Christine and Fisher, Helen

Available at http://clok.uclan.ac.uk/6721/

Radford, Lorraine ORCID: 0000-0002-6095-3845, Corral, Susana, Bradley, Christine and Fisher, Helen (2013) The prevalence and impact of child maltreatment and other types of victimization in the UK: Findings from a population survey of caregivers, children and young people and young adults. Child Abuse and Neglect, 37 (10). pp. 801-813. ISSN 0145-2134

It is advisable to refer to the publisher's version if you intend to cite from the work. http://dx.doi.org/10.1016/j.chiabu.2013.02.004

For more information about UCLan's research in this area go to http://www.uclan.ac.uk/researchgroups/ and search for <name of research Group>.

For information about Research generally at UCLan please go to http://www.uclan.ac.uk/research/

All outputs in CLoK are protected by Intellectual Property Rights law, including Copyright law. Copyright, IPR and Moral Rights for the works on this site are retained by the individual authors and/or other copyright owners. Terms and conditions for use of this material are defined in the policies page. 
The prevalence and impact of child maltreatment and other types of victimization in the UK: Findings from a population survey of caregivers, children and young people and young adults.

\begin{abstract}
Objectives: To measure the prevalence of maltreatment and other types of victimization among children, young people and young adults in the UK; to explore the risks of other types of victimization among maltreated children and young people at different ages; using standardised scores from self-report measures, to assess the emotional wellbeing of maltreated children, young people and young adults taking into account other types of childhood victimization, different perpetrators, non-victimization adversities and variables known to influence mental health. Methods: A random UK representative sample of 2,160 parents and caregivers, 2,275 children and young people and 1,761 young adults completed computer-assisted self-interviews. Interviews included assessment of a wide range of childhood victimization experiences and measures of impact on mental health.
\end{abstract}

Results: $2.5 \%$ of children aged under 11 years, $6 \%$ of children and young people aged 11 to 17 years had one or more experiences of physical, sexual or emotional abuse, or neglect by a parent or caregiver in the past year and $8.9 \%$ of children under 11 years, $21.9 \%$ of young people aged 11 to 17 years and $24.5 \%$ of young adults had experienced this at least once during childhood. High rates of sexual victimization were found, 7.2\% of females aged 11 to 17 and $18.6 \%$ of females aged 18 to 24 reporting childhood experiences of sexual victimization by any adult or peer that involved physical contact (from rape to sexual touching). Victimization experiences accumulated with age and overlapped. Children who experienced maltreatment from a parent or caregiver were more likely than those not 
maltreated to be exposed to other forms of victimization, to experience non-victimization adversity, a high level of polyvictimization and to have higher levels of trauma symptoms. Conclusions: The past year maltreatment rates for children under age 18 were seven to seventeen times greater than official rates of substantiated child maltreatment in the UK. Professionals working with children and young people in all settings should be alert to the overlapping and age related differences in experiences of childhood victimization to better identify child maltreatment and prevent the accumulative impact of different victimizations upon children’s mental health.

Keywords: Child maltreatment, sexual abuse, child victimization, prevalence of child abuse, polyvictimization. 
The prevalence and impact of child maltreatment and other types of victimization in the UK: Findings from a population survey of caregivers, children, and young people and young adults

Worldwide child maltreatment is recognised as a significant public health concern but there is no consensus among researchers on the extent of the problem and whether nationally or globally rates of maltreatment are increasing or declining (Finkelhor \& Jones, 2006;

Finkelhor, Turner, Omrod \& Hamby, 2010; Gilbert et al, 2011; Trocme et al., 2008). There has been an increase in child protection activity across the UK in recent years with growing numbers of children having child protection plans or being placed in local authority and foster care. The number of children subject to child protection plans in England increased by 48\% from 26,400 in 2006 (Department for Children, Schools and Families [DCSF], 2009) to 39,100 in 2010 (Department of Education [DfE], 2010) and data from Wales, Northern Ireland and Scotland show similar upward trends (Author, 2011). Up to now, estimates of the prevalence of child maltreatment in the UK have drawn mostly from one research study, based on 2,869 (retrospective) interviews with young adults under the age of 25, conducted in 1998-9 (Cawson, Wattan, Brooker \& Kelly, 2000; May-Chahal \& Cawson, 2005). No comprehensive data has been available in the UK on the rates of maltreatment and other types of victimization reported by children and young people themselves.

It is acknowledged that rates of maltreatment recorded by child protection services are lower than the prevalence in the general population. Many cases are not identified, reported nor given a service response (Munro, 2011). The extent of the gap between the recorded/reported cases and levels of prevalence in the general child population is hard to assess because child maltreatment often occurs in the home or in private settings where both detection and disclosure are more difficult. Child maltreatment is hard to talk about, developmental factors will influence the extent to which abuse or neglect is recognised and named as such by the 
victim. Many research studies have asked adults rather than children themselves about childhood experiences although abuse can have an impact on memory and the ability to recall accurately (Maughan \& Rutter, 1997). While research suggests that at least half to a majority of young adults do remember experiences of childhood abuse when asked, an individual may be less likely to recall if they were young at the time of the abuse or more likely to recall if the experience was unusual or consequential (Hardt \& Rutter, 2004). Self-report studies generally produce higher prevalence rates in victimization research (Everson et al, 2008), but estimates of the prevalence of child maltreatment and other types of victimization vary widely not only across different regions but also between different studies collecting data within the same nations (Stoltenberg, van Ijzendoorn, Euser \& Bakermans-Kranenburg, 2011). For example, studies of child sexual abuse in the UK produce very different lifetime prevalence estimates showing between 13\% (Oaksford \& Frude, 2001) to 21\% of females are affected (May-Chahal \& Cawson, 2005). Variations in prevalence rates are thought to be partly due to methodological differences in definitions, data collection methods, measures of victimization and participant sampling, which is sometimes not representative of the current child population (Pereda, Guilera, Forns \& Gómez-Benito, 2009). Epidemiological information is needed to define the problem conceptually, describe the scale of maltreatment and the characteristics of those most affected. A more standardized epidemiological approach which permits comparison and contrast of rates of prevalence across time and different regions would facilitate international efforts to plan, respond to and prevent child abuse.

The harm caused by child maltreatment to health and wellbeing can last into adult life, abuse being a factor in adult mental health difficulties such as psychosis (Fisher et al, 2010). There is evidence that victimization experiences vary developmentally, are cumulative and interrelated (Edwards, Holden, Felitti \& Anda, 2003; Herrenkohl \& Herrenkohl, 2009). However 
many studies have focused on a single 'type' victimization (such as child sexual abuse or physical violence by caregivers) and relatively few studies have considered child maltreatment in the context of other victimizations that children and young people experience at home, in school, in other settings and in the communities where they live. The co-occurrence of child maltreatment by caregivers with other types of victimization, whether by adults or by peer, has been supported in the research literature and empirically tested, with exposure to specific forms of victimization shown to be good predictors of other types (Finkelhor, Ormrod, Turner, \& Holt, 2009). Outcomes for children are most likely to be poorer where there have been other adverse experiences and multiple and /or polyvictimizations (Appleyard, Egeland, van Dulman \& Stroufe, 2005; Turner, Finkelhor \& Ormrod, 2006). Demonstrating the impact of these inter-related, developmentally varying and cumulative aspects of victimization on the wellbeing of children and young people could help to encourage earlier identification of those who are vulnerable as well as a more holistic approach to maltreatment prevention.

This paper aims to:

- Establish lifetime and past year prevalence rates of child maltreatment and other types of childhood victimization in the UK population, drawing from interviews with a representative sample of caregivers, young people and young adults:

- Explore the risk of other types of victimization among maltreated children and young people of different ages;

- Using standardised scores from self-report measures, assess the emotional wellbeing of maltreated children, young people and young adults, taking into account other types of victimization, different types of perpetrators, non-victimization adversities and other variables known to influence mental health. 


\section{Method}

Participants

A random probability sampling approach was used to select households from the UK Postcode Address File. Advance letters were sent to around 50,000 households in England, Scotland, Northern Ireland and Wales. Letters were followed up with visits to check eligibility (i.e. a person aged under 25 was resident in the house) and obtain consent. If there was more than one child in the appropriate age range within a household, a Kish grid was used to randomly select one child under the age of 18 . The overall response rate for the research was $60.4 \%$.

In total, 2,160 parents or caregivers of children aged between 2 months and 10 years, 2,275 children and young people aged between 11 and 17 and their parent or caregiver and 1,761 young adults aged 18 to 24 years were interviewed at home between March and December 2009. There were slightly more female children, young people and young adults in the sample than males (51.6\% females, $48.4 \%$ males). The average (mean) age of children under 11 was 4.6 years ( $s d=3.16$ ), for young people aged $11-17$ it was 14.0 years $(s d=1.98)$ and for young adults aged 18 to 24 it was 20.6 years $(s d=1.98)$. Most parents or caregivers were female ( $\mathrm{N}=3,750,84.7 \%)$. This uneven gender spread reflects the parents' own definitions of who was the primary caregiver. The vast majority of children and young people had White British ethnicity (82.2\%), while 3.4\% were 'Other White', $3.5 \%$ were Mixed, 5.3\% South Asian, 3.1\% Black British, African or African Caribbean and 2.2\% were Chinese or from other ethnic groups.

\section{Procedure}

TNS-BMRB, a specialist social research company, was commissioned to conduct the fieldwork interviews. Drawing upon established practice for victimization surveys in the 
UK, such as the British Crime Survey (Chaplin, Flatley \& Smith, 2011), computer-assisted self-interviewing (CASI) techniques were used in households and young people were also given the option of using headphones (audio CASI) to listen to the questions privately. Written consent was required from parents of anyone under age 18. For participants aged 11 to 17 , consent was also independently agreed with the child or young person and reaffirmed on screen at the start of the computer interview (Author, 2012). Caregivers completed the whole interview on behalf of children under 11 . For young people aged 11-17, the primary caregiver (as defined by the parents themselves) was interviewed first and asked questions about the family in general. The young person then completed a computer interview on experiences of victimization. Interviewers were instructed to make sure the young person could complete the computer interview without being overlooked. The caregiver was given a paper questionnaire to complete at the same time.

Participants were provided with opportunities throughout the CASI interview to indicate if they wished to talk to someone and interviewers handed out de-brief sheets at the end of the interview which included contact details for relevant support services. As part of the ethical protocol developed for the research, certain items in the questionnaire were automatically 'red flagged', so that when participants responded positively to these questions a summary was sent to the research team who reviewed the information for indicators of immediate danger and alerted child protection services where necessary. The potential for such breaches of confidentiality was stressed to participants during the consent process and also during the computerised interview. The research was approved by the NSPCC research ethics committee and an on-going process of ethical scrutiny by independent experts was in place throughout the study. 
A modified version of the Juvenile Victimization Questionnaire (JVQ; Hamby, Finkelhor, Ormrod, \& Turner, 2004) was used to assess exposure to a broad range of maltreatment and victimization experiences. The JVQ has 35 items, arranged in 5 modules, i.e., conventional crime, child maltreatment, peer and sibling victimization, sexual victimization, witnessing and indirect victimization. The JVQ caregiver version (Hamby, Finkelhor, Ormrod, \& Turner, 2004), was completed by a parent or caregiver on behalf of the child, if aged between 2 months to 10 years. Children and young people between ages 11 to 17 years completed the Child Self-Report Version (Hamby et al., 2004). Questions from the JVQ Child Self Report Version were adapted to ask young adults retrospectively about childhood victimization experiences (before the age of 18).

In this study, 26 of the original JVQ items were used. Two of the JVQ items on sexual abuse were merged into one question. Two new questions were added: a question on sexual abuse of those aged 16 and 17 by an adult in a position of trust (to reflect the law in the UK) and a question on a caregiver shaking or shoving a child. The JVQ has just one screener question on neglect prompting children and young people to think about neglect in terms of lack of physical care, medical attention and not having a safe space to stay. In addition to the JVQ neglect screener question, 13 age-specific additional questions were used to assess neglect as defined in guidance from UK governments (HM Government, 2010). These questions covered absence of physical care, medical care, educational neglect, lack of supervision and monitoring, and emotional neglect (further information is given in the appendix and in Author, 2011Follow up questions were asked to assess whether the victimization experience had happened in the past year, how often it had happened, who the perpetrator had been and the victim's perceptions of the experience as violent or abusive. The two most severe victimization events reported by each participant were followed up in more detail with an 
extended set of questions including the level of physical injury and upset, whether the young person had told anybody and had any contact with services or sources of support.

An adapted version of the non-victimization adversity measure described by Turner et al. (2006) was employed to assess non-violent traumas and chronic stressors that occurred to participants during their lifetime. This contained 9 items covering accidents, serious illnesses, deaths, homelessness, substance misuse amongst family members, parental separation and imprisonment (further details are in Author, 2011).

To assess the child's mental health over the past month, caregivers of children aged 3 to 10 years completed a shortened 26-item version of the Trauma Symptom Checklist for Young Children (TSCYC; Briere et al, 2001). Young people aged 11 to 17 years completed for themselves a shortened version of the Trauma Symptom Checklist for Children (TSCC; Briere, 1996). Young adults aged 18 to 24 completed the 40 item version of the Trauma Symptom Checklist (Briere \& Runtz, 1989). All of these instruments demonstrated high levels of internal consistency using Cronbach's alpha statistic (TSCYC: $\alpha=0.84$; TSCC: $\alpha=0.91$; $\operatorname{TSC} \alpha=0.93)$.

\section{Data analysis}

Weights were applied to all analyses to compensate for unequal sampling probabilities, and unequal responses by age group, gender, housing tenure, working status, region and ethnic group. Analyses were conducted separately for each of the three age groups in the study. Composites from JVQ and NSPCC items (shown in the Appendix) were created to show past year (ages under 18 ) and lifetime experiences of different types of childhood victimization (all three age groups). These included child maltreatment, neglect, emotional abuse, physical violence, sexual victimization, exposure to domestic violence and witnessing violence in the community. Composites from JVQ and NSPCC items (shown in the 
Appendix) were then created to show victimization by different types of perpetrators. These included:

- maltreatment by parents or caregivers (any physical, sexual, emotional abuse or neglect by the parent or caregiver or parent/caregiver’s partner, excluding exposure to parental domestic violence which was assessed separately);

- maltreatment by adults not living in the family home (any physical, sexual or emotional abuse of the child by an adult other than a parent or caregiver or parents' partner)

- victimization by peers (any physical violence, sexual victimization or emotional abuse by another young person aged under 18, excluding any victimization by the young person's siblings or intimate partner);

- victimization by siblings (any physical violence, sexual victimization or emotional abuse by a sibling under the age of 18);

- victimization of a young person over the age of 11 years by the young person's intimate partner (any physical violence, sexual victimization or emotional abuse by an intimate partner aged under or over 18).

The following composite variables were also created from the JVQ items, including property victimization, to assess rates of polyvictimization among the three age groups in the study:

- a continuous variable based on the sum of different types of victimization in childhood;

- a dichotomous variable to measure 'high polyvictimization' (coded $0=$ not high PV, $1=$ high PV). This was defined as the $10 \%$ among the polyvictimized with the greatest total number of different victimization experiences (6+ for those aged under $11,13+$ for those aged 11 to $17,15+$ for those aged 18 to 24$)$. 
To simplify the presentation of findings and to provide consistency with other published research (Finkelhor, Ormond, \& Turner, 2007), overall trauma symptom scores were calculated by summing the responses for each child, young person or young adult for the TSCYC, the TSCC and the TSC, respectively. These total scores were standardised using the mean and standard deviation for the relevant age group and then merged together to create an overall trauma score to allow comparison between participants of different ages. Analyses were conducted separately for each age group (3-10, 11-17 and 18-24) due to the different mental health measures and informants used (caregiver versus child/young person and young adult). Data on trauma for children under age 3 years was too limited to allow meaningful analysis and is excluded.

Logistic regressions were used to test the likelihood of experiencing other victimizations among those victimized. Odds ratios were calculated controlling for age, gender, ethnicity, other non-victimization adversities and social grade (Social grade was the parents' highest occupational status at the time of interview as defined by the British National Readership Survey social grading scale where AB - higher and intermediate managerial, administrative or professional occupations; C1 - supervisory, clerical or junior managerial, administrative or professional occupations; C2 - skilled manual workers; and DE - semi and unskilled manual workers, state pensioners, casual or lowest grade workers, or unemployed with state benefits only). As the incidence of the outcomes of interest (eg., selected victimizations) was relatively common in the sample, the derived odds ratios were converted to risk ratios (Zhang and Yu, 1998).

Hierarchical multiple regressions were performed, controlling for age of child at interview, ethnicity, gender, non-victimization adversity and social grade, to test associations between trauma symptom scores and different types of victimization, by different perpetrators and high polyvictimization. 


\section{Results}

Table 1 presents the prevalence rates of past year and lifetime victimization by age group, child gender and perpetrator type.

$<$ Insert Table 1 here $>$

Victimization by peers or siblings was the most prevalent experience. Maltreatment by parents or caregivers however affected a large minority of children and young people during childhood. Apart from sibling victimization, higher rates for all forms of childhood victimization were reported for older age groups, with young adults aged 18 to 24 (retrospectively) reporting highest rates. This is to be expected as victimization experiences tend to accumulate with age. There were no significant differences found for the frequency of reports made by males and females of child maltreatment by a parent or caregiver and exposure to parental domestic violence. Females in the older two age groups reported significantly more sexual victimization than males. Males reported more physical violence from non-caregivers and more witnessing violence in the community.

$<$ Insert Table 2 here $>$

Table 2 summarises lifetime and past year experiences of different types of child maltreatment and other victimizations. Parental neglect was found to be the most prevalent form of lifetime child maltreatment in the family. The frequency of sexual abuse by a parent or caregiver was low but reporting may have been affected by the method of data collection in the family home. Those aged 11 to 17 and 18 to 24 reported high rates of sexual victimization during childhood, with nearly 1 in 14 girls aged 11 to 17 and 1 in 5 girls aged 18 to 24 reporting childhood experiences of sexual victimisation that involved physical contact (from rape to sexual touching). The childhood and past year rates of sexual victimization for older females were high, with 1 in 5 (20.1\%) of those aged 15 at the time of 
interview reporting sexual victimization in the past year, $13.2 \%$ of females and $3.7 \%$ of males aged 15 to 17 years reporting an experience of contact sexual abuse in childhood. Young people under age 18 were perpetrators in $65.9 \%$ of cases of contact sexual abuse. Data on victimization in the past twelve months present a better estimate of current prevalence. Some relatively small differences were observed between reports made by caregivers on behalf of children aged under 11 and those made by young people themselves at ages 11 to 17 although we cannot be sure to what extent these are reporter-related or agerelated differences. Caregivers might not know or want to disclose everything a child had experienced in the past year. To illustrate the variations by age in past year rates of different types of victimization, Figure 1 shows reports (from caregivers) for children aged 10 and youth self-reports from to ages 11 through to 17.

$<$ Insert Figure 1 here >

The data from the youth past year victimization self-reports give some support to the developmental victimology perspective. Figure 1 shows a decline between ages 10 and 17 in past year rates of victimization by siblings and an increase in rates of victimization by an intimate partner from ages 11 to 17 . All other past year victimization experiences, apart from exposure to parental domestic violence, rise from ages 11 to 12, peak between ages 13 to 16 and then decline.

\section{Experiencing other types of victimization}

To test the co-occurrence of maltreatment and other victimization types, odds ratios were calculated via logistic regression, and then converted to risk ratios, controlling for age, gender, ethnicity, social grade, and other non-victimization adversities. From these results, it is evident that children and young people who experience maltreatment from a parent or 
caregiver are at greater risk than those who are not-maltreated of experiencing victimization from others and witnessing domestic violence (Table 3).

$<$ Insert Table 3 here $>$

In general, across all three age groups, those who had been maltreated by a parent or caregiver in childhood had significantly higher risks of also experiencing victimization by siblings, peers, an intimate partner, a non-resident adult and being exposed to domestic violence. Apart from the risk of exposure to domestic violence among maltreated children, the risks of experiencing other types of childhood victimization were higher among young people and young adults self-reporting on their experiences than they were among children aged under 11 where the caregiver reported on the child's behalf. The highest levels of relative risk of experiencing other types of victimization were found among those who had experienced physical violence in childhood, whetherfrom a parent or caregiver or or from another person not living with the child.

\section{Impact - emotional well being}

Tables 4, 5 and 6 present the results for each age group from multiple hierarchical regressions conducted to test the independent effects of selected victimization types (step 3) and high polyvictimization (step 4) on trauma scores, while controlling for demographic factors ,non-victimization adversity (step 1),other types of victimization, and victimization by different perpetrators (step 2).

\section{$<$ Insert Tables 4, 5 \& 6 here >}

Higher trauma scores for all three age groups were associated with maltreatment by a caregiver, victimization by peers and high levels of polyvictimization. Young people aged 11 to 17 and young adults aged 18 to 24 who experienced sexual or intimate partner victimization also had significantly higher trauma scores. Different types of victimization 
had varied impact by age group. Victimization by siblings was associated with higher trauma scores for children aged under 11 but this was not the case for young people aged 11 to 17 and for the young adults surveyed. Maltreatment by a non-resident adult was significantly associated with higher trauma symptoms for children and young people aged under 18 but not for the young adults. Exposure to community violence was only significantly associated with higher trauma scores for young adults. Polyvictimization was less significant for children aged under 11 than for the older children and young adults.

\section{Discussion}

The main objective of this study was to assess the prevalence and impact of lifetime and past year maltreatment and other victimizations among children in the UK. Our findings show there is a substantial gap between known, substantiated cases of child maltreatment, as measured by the number of children in the UK subject to a child protection plan (in 2009 46,679 children; DfE, 2010), which is $0.35 \%$ of the child population and the $2.5 \%$ (caregiver reported for children aged under 11) to $6 \%$ (young person aged 11 to 17 reported) rates for the prevalence of maltreatment in the past year reported in this research. The rates of maltreatment in the population each year are seven to seventeen times greater than the substantiated cases recorded by child protection services. Of course there are likely to be differences between experiences of maltreatment children and young people self-report in social surveys and the cases of maltreatment that come to the attention of child protection services. Other researchers using multiple data sources have estimated that only one out of every thirty cases of child maltreatment is recognised in official statistics (Gilbert et al, 2011). These findings suggest there is a high level of unrecognised need among maltreated children and young people in the UK. 
We found few differences between rates of child maltreatment by parents and caregivers reported by males and females. Looking at other types of childhood victimization, males experienced more victimization by peers, more physical violence from non-caregivers and more exposure to community violence, while females in the two older age groups reported more experiences of sexual victimization than males. The past year rates of sexual victimization for older females were high, with 1 in 5 (20.1\%) of those aged 15 at the time of interview reporting sexual victimization in the past year. Lifetime rates of child maltreatment and contact sexual abuse reported by young adults were similar to those found in the earlier research conducted for the NSPCC in 1989-9 (May-Chahal \& Cawson, 2005), where 25\% of young adults had some lifetime maltreatment, compared with $26.5 \%$ in the current study, $15 \%$ reported some neglect (defined by May- Chahal \& Cawson as serious or intermediate absence of care), compared with 16\% reporting neglect in the current study and $11 \%$ reported contact sexual abuse, compared with $12.5 \%$ in the current study. Differences were greater for peer victimization, with $63.2 \%$ of young adults reporting peer victimization during childhood in the current study compared with $42 \%$ who reported some 'bullying' by adults or peers outside the home in the research conducted in 1998-9. The current study included a wider range of questions about victimization by peers and this may account for some of this difference.

A meta-analysis of research on child sexual abuse prevalence found lifetime rates of $13.5 \%$ for females and 5.6\% for males for research conducted in countries in Europe (Stoltenborgh et al., 2011). Lifetime rates of sexual victimization in the current research were higher for young people aged 11 to 17 (20.8\% females, $12.5 \%$ males) and young adults reporting on experiences before the age of 18 ( $31 \%$ females, $17.4 \%$ males). This is likely to have been influenced by the inclusion of peer to peer sexual victimization in the current research. Where other researchers have included peer sexual victimization, the rates for the UK are 
comparatively lower. For example, Averdijk, Eisner and Mueller-Johnson (2011) found $8.1 \%$ males and $21.7 \%$ of females aged 15 to 17 in schools in Switzerland reported childhood experiences of contact sexual victimization compared with $13.2 \%$ of females and $3.7 \%$ of males reporting experiences of contact sexual abuse in this research. The past year prevalence rates of child maltreatment for the UK are also lower than those reported in some other high income nations even where similar questions were used from the JVQ to assess rates of maltreatment (Elloneni \& Salmi, 2011; Finkelhor, Turner, Ormrod \& Hamby, 2009). Further research is needed to establish whether these apparent differences reflect actual variations in levels of child maltreatment across high income countries or if the variations in prevalence rates are the result of methodological differences or possibly the result of cultural factors influencing respondents' readiness to disclose victimization to social surveys. Research that includes qualitative and context specific questions about the broader environment and policy context could aid understanding. Gathering data from multiple indicators but including self-report studies could also produce a better triangulation of the data (Gilbert et al, 2011).

Similar to other research that has considered a wide range of victimization experiences and other adversities in childhood (Herrenkohl \& Herrenkohl, 2009) this study found an accumulation in the number and range of victimizations with age. Older children and young people had a greater mean number of lifetime and past year victimization experiences. Risks of further victimizations for maltreated children and young people are likely to be partly the result of lack of supervision, partly due to risk taking behaviour which is known to be a consequence of living with abuse and possibly also because the maltreated and neglected child might be singled out by adults or peers as vulnerable or 'different'. Rates of past year experiences of child maltreatment by parents or caregivers did not decline for older children and young people, indicating that the importance of professionals remaining alert to the 
continued risks towards older children of experiencing victimization at home, at school and in the community.

Our findings for the UK endorse other research conducted outside the UK that has shown the overlapping and accumulative nature of child maltreatment and sexual victimization with other types of victimization in childhood. This gives further support for the early identification of children in need and providing early help, no matter what the age of the child (Munro, 2011). For maltreatment by a parent or caregiver the increased risks of experiencing other types of victimization were significantly greater for the older age groups self-reporting childhood experiences. Confirming other research findings (Elloneni \& Salmi, 2011; Finkelhor, Ormrod \& Turner, 2007) we found that polyvictimized children and young people in the UK were particularly likely to have elevated trauma symptom scores.

\section{Limitations}

There are a number of limitations to this research that should be acknowledged. The data on the prevalence and impact for child maltreatment and victimization were collected in a crosssectional study and therefore can only indicate potential associations between victimization and trauma symptoms and cannot provide any evidence of cause and effect. Longitudinal designs involving prospective assessments would be required to disentangle the temporal ordering of victimization and emotional problems.

\section{Practice implications}

Our findings suggest a number of practice and policy implications. There is a sizeable gap between the number of children with child protection plans and the number reported by this research to have been maltreated recently indicating that a high level of unmet need still exists in the general population of children and young people in the UK. To identify and 
respond in a timely manner, adults who work with children and young people in all agencies should be alert to varied age related risks and the overlapping nature of maltreatment with other types of child victimization.

Preventive education with children and young people (in schools or in community awareness campaigns) should address the age related/developmental variations in maltreatment experiences, risks and impact. The focus for younger children needs to be on risks from adults and young people in the family or known by the family. The finding that $65.9 \%$ of contact sexual abuse towards older children was perpetrated by other young people under the age of 18 should be examined closely and used to inform preventive interventions. Finally, school and community based violence prevention with older children should expand the focus of anti-bullying or healthy relationships projects to include the prevention of risks from all forms of victimization (sexual, intimate partner, parental maltreatment, peer and community).

\section{Role of the funding source}

The research was funded by the NSPCC, the Children's Charity and British Home Stores.

Helen L. Fisher was supported by an interdisciplinary postdoctoral fellowship from the Medical Research Council (MRC) and Economic and Social Research Council (ESRC), UK. The NSPCC was involved in study design but none of the funders were involved in the analysis and interpretation of data; in the writing of the report; and in the decision to submit the article for publication. 


\section{References}

Author (2011).

Author (2012).

Appleyard, K., Egeland, B., van Dulmen, M. H. M., \& Sroufe, L. A. (2005). When more is not better: The role of cumulative risk in child behavior outcomes. Journal of Child Psychology \& Psychiatry, 46(3), 235-245. doi:10.1111/j.1469-7610.2004.00351.x

Averdijk, M., Eisner, M., \& Mueller-Johnson, K. (2011). Sexual victimization among adolescents in Switzerland. Geneva: Optimus Foundation.

Briere, J. (1996). Trauma Symptom Checklist for Children (TSCC) professional manual. Odessa, FL: Psychological Assessment Resources.

Briere, J., Johnson, K., Bissada, A., Damon, L., Crouch, J., Gil, E., Hanson, R., \& Ernst, V. (2001). The Trauma Symptom Checklist for Young Children (TSCYC): reliability and association with abuse exposure in a multi-site study. Child Abuse and Neglect, 25, 10011014. doi:10.1016/S0145-2134(01)00253-8.

Briere, J. \& Runtz, M. (1989) The Trauma Symptom Checklist (TSC-33): Early data on a new scale. Journal of Interpersonal Violence, 4(2) 151-163. doi:10.1177/088626089004002002.

Cawson, P., Wattam, C., Brooker, S., \& Kelly, G. (2000). Child maltreatment in the United Kingdom. London: NSPCC.

Chaplin, R Flatley, J. \& Smith, K. (2011). Crime in England and Wales 2010-11: Findings from the British Crime Survey and Police Recorded Crime ( $2^{\text {nd }}$ Ed.). London: Home Office. Retrieved from http://www.homeoffice.gov.uk/publications/science-researchstatistics/research-statistics/crime-research/hosb1011/hosb1011?view=Binary. 
Department for Children, Schools and Families. (2009). Referrals, assessments and children and young people who are the subject of a child protection plan, England - year ending 31 March 2009. Retrieved from www.dcsf.gov.uk/rsgateway/DB/SFR/s000873/index.shtml. Department for Education. (2010). Referrals, assessments and children who were the subject of a child protection plan (children in need census - final) year ending 31 March 2010. Retrieved from www.education.gov.uk/rsgateway/DB/STR/d000970/index.shtml.

Edwards, V. J., Holden, G.W., Felitti, V.J., \& Anda, R.F. (2003). Relationship between multiple forms of childhood maltreatment and adult mental health in community respondents: results from the adverse childhood experiences study. The American Journal of Psychiatry, 160, 1453-1460. doi:10.1176/appi.ajp.160.8.1453.

Elloneni, N., \& Salmi, V. (2011). Polyvictimization as a life condition: correlates of polyvictimization among Finnish children. Journal of Scandinavian Studies in Criminology and Crime Prevention, 12(1), 20-44. doi:10.1080/14043858.2011.561621.

Everson, M. D., Smith, J. B., Hussey, J. M., English, D., Litrownik, A. J., Dubowitz, H. Thompson, R., Knight, E. D., \& Runyan, D. K. (2008). Concordance between adolescent reports of childhood abuse and child protective service determinations in an at-risk sample of young adolescents. Child Maltreatment, 13(1) 14-26. doi:10.1177/1077559507307837.

Finklehor, D., \& Jones L. (2006). Why have child maltreatment and child victimization declined? Journal of Social Issues, 62(4), 685-716. doi:10.1111/j.15404560.2006.00483.x.

Finkelhor, D., Hamby, S. L., Ormrod, R., \& Turner, H. (2005). The Juvenile Victimization Questionnaire: reliability, validity, and national norms. Child Abuse and Neglect, 29, 383412. doi:10.1016/j.chiabu.2004.11.001. 
Finkelhor, D., Ormrod, R. K., \& Turner, H. A. (2007). Poly-victimization: a neglected component in child victimization. Child Abuse and Neglect, 31, 7-26. doi:10.1016/j.chiabu.2006.06.008.

Finkelhor, D., Ormrod, R., Turner, H., \& Holt, M. (2009). Pathways to poly-victimization. Child Maltreatment, 14, 316-329. doi: 10.1177/1077559509347012.

Finkelhor, D., Turner, H., Ormrod, R., \& Hamby, S. L. (2009). Violence, abuse, and crime exposure in a national sample of children and youth. Pediatrics, 124(5), 1411-1423. doi:10.1542/peds.2009-0467.

Finkelhor, D., Turner, H., Ormrod, R., \& Hamby, S. (2010). Trends in childhood violence and abuse exposure: Evidence from two national surveys. Archives in Pediatrics and Adolescent Medicine, 164, 238-242.

Fisher, H. L., Jones, P. B., Fearon, P., Craig, T. K., Dazzan, P., Morgan, K., Hutchinson, G., Doody, G. A., McGuffin, P., Leff, J., Murray, R. M., \& Morgan, C. (2010). The varying impact of type, timing and frequency of exposure to childhood adversity on its association with adult psychotic disorder. Psychological Medicine, 40(12), 1967-1978. doi:10.1017/S0033291710000231.

Gilbert, R. Fluke, J. O’Donnell, M. Gonzalez-Izquierdo, A. Brownwell, M. Gulliver, P. Janson, S \& Sidebotham, P. (2011). Child maltreatment: variation in trends and policies in six developed countries. The Lancet, Early Online Publication. doi:10.1016/S01406736(11)61087-8.

Departament for Children, Schools and Families. (2010). Working together to safeguard children: A guide to inter-agency working to safeguard and promote the welfare of children. Available at https://www.education.gov.uk/publications/standard/publicationDetail/Page1/DCSF00305-2010. 
Hamby, S. Finkelhor, D., Ormrod, D., \& Turner, H. (2004). The comprehensive JVQ administration and scoring manual. Durham, NH: University of New Hampshire, Crimes Against Children Research Centre.

Hardt, J., \& Rutter, M. (2004). Validity of adult retrospective reports of adverse childhood experiences: a review of the evidence. Journal of Child Psychology and Psychiatry, 45, 260-273. doi:10.1111/j.1469-7610.2004.00218.x.

Herrenkohl, R. \& Herrenkohl, T. (2009). Assessing a child's experience of multiple maltreatment types: some unfinished business. Journal of Family Violence, 24, 485-496. doi:10.1007/s10896-009-9247-2.

Maughan, B., \& Rutter, M. (1997). Retrospective reporting of childhood adversity: issues in assessing long-term recall. Journal of Personality Disorders, 11, 19-33. doi:10.1521/pedi.1997.11.1.19.

May-Chahal, C., \& Cawson, P. (2005). Measuring child maltreatment in the United Kingdom: a study of the prevalence of child abuse and neglect. Child Abuse and Neglect, 29, 969-984. doi:10.1016/j.chiabu.2004.05.009.

Munro, E. (2011). The Munro review of child protection: final report. A child-centred system. Retrieved from http://www.education.gov.uk/munroreview/downloads/8875_DfE_Munro_Report_TAGG ED.pdf.

Oaksford, K. L. and Frude, N. (2001). The prevalence and nature of child sexual abuse: evidence from a female university sample in the UK. Child Abuse Review, 10(1) 49-59. doi:10.1002/car.663.

Pereda, N., Guilera, G., Forns, M., \& Gómez-Benito, J. (2009). The prevalence of child sexual abuse in community and student samples: A meta-analysis. Clinical Psychology Review, 29(4), 328-338. doi:10.1016/j.cpr.2009.02.007. 
Stoltenborgh, M., van Ijzendoorn, M., Euser, E., \& Bakermans-Kranenburg, M. (2011). A global perspective on child sexual abuse: meta analysis of prevalence around the world. Child Maltreatment, 16(2), 79-101. doi:10.1177/1077559511403920.

Trocmé, N., Fallon, B., MacLaurin, B., Sinha, V., Black, T., Fast, E., ... Holroyd, J. (2008). The Canadian incidence study of reported child abuse and neglect. Ontario, Canada: Public Health Agency. Available at http://www.phac-aspc.gc.ca/cm-vee/public-eng.php. Turner, H. A., Finkelhor, D., \& Ormrod, R. (2006). The effect of lifetime victimization on the mental health of children and adolescents. Social Science and Medicine, 62(1), 13-27. doi:10.1016/j.socscimed.2005.05.030.

Zhang, J., \& Yu, K. (1998). What's the relative risk? A method of correcting the odds ratios in cohort studies of common outcomes. Journal of the American Medical Association, 280, 1690-1691. 
Appendix. Screener questions and composites used from Juvenile Victimisation Questionnaire (youth self-report version) and NSPCC 2000 survey.

JVQ Module: Conventional Crime - Items marked *denote items included in composites for physical violence; ${ }^{\mathrm{x}}$ emotional abuse; ${ }^{\mathrm{v}}$ property victimization.

1. ${ }^{\mathrm{v}}$ Force (age 2+) At any time in your life, did anyone USE FORCE to take something away from you that you were

2. Steal (age $2+$ ) carrying or wearing?

3. ${ }^{\mathrm{v}}$ Break (age $2+$ ) At any time in your life, did anyone steal something from you and never give it back? Things like a backpack, money, watch, clothing, bike, stereo, mobile phone or anything else?

4.*Armed (all ages) At any time in your life, did anyone break or ruin any of your things on purpose? Sometimes people are attacked WITH sticks, rocks, guns, knives, or other things that would hurt. At any time in your life, did anyone hit or attack you on purpose WITH an object or weapon?

5.*Unarmed (all ages) 6.*Attempt (all ages) At any time in your life, did anyone hit or attack you WITHOUT using an object or weapon? At any time in your life, did someone start to attack you, but for some reason, IT DIDN'T HAPPEN? For example, someone helped you or you got away?

7. ${ }^{\mathrm{x}}$ Threat (age $2+$ )

8.*Kidnap (all ages) At any time in your life, did someone threaten to hurt you and you thought they might really do it? When a person is kidnapped, it means they were made to go somewhere, like into a car, by someone who they thought might hurt them. At any time in your life, has anyone ever tried to kidnap you)?

9.*Prejudice (age 2+) At any time in your life, have you been hit or attacked because of your skin colour, religion, or where your family comes from, because of a physical or learning problem you have or because someone said you were gay?

JVQ Module: Child Maltreatment- Items marked *denote items included in composites for physical violence; ${ }^{\mathrm{x}}$ emotional abuse

10.*Hurt adult (all ages) Not including smacking, at any time in your life did a grown-up in your life hit, beat, kick, or physically hurt you in any way?

11. ${ }^{\mathrm{x}}$ Scared adult (age

2+) At any time in your life, did you get scared or feel really bad because grown-ups in your life called you names, said mean things to you, or said they didn't want you?

12.*Hide (all ages) Sometimes a family argues over where a child should live. At any time in your life, did a parent take, keep, or hide you to stop you from being with another parent?

13.*Shake (NSPCC) (all At any time in your life, did a grown up in your life shake you very hard or shove you against a ages) wall or a piece of furniture?

JVQ Module: Peer and Sibling Victimization Items marked *denote items included in composites for physical violence; xemotional abuse

14.*Gang (age $2+$ )

15.*Hit child (all ages) Sometimes groups of children or young people, or gangs, attack people. At any time in your life, did a group or a gang hit, jump, or attack you?

16.*Private (age 2+) $\quad$ At any time in your life, did any children or young people try to hurt your private parts on purpose At any time in your life, did any child or young person, even a brother or sister, hit or kick you? Somewhere like: at home, at school, out playing, in a shop, or anywhere else?

17. ${ }^{\mathrm{x}}$ Picked (age $2+$ ) by hitting or kicking you there?

18. ${ }^{\mathrm{x}}$ Scared child (age At any time in your life, did any children or young people, even a brother or sister, pick on you..by chasing you, or grabbing you or by making you do something you didn't want to do?

$2+)$ At any time in your life, did you get really scared or feel really bad because children or young people were calling you names, saying mean things to you, or saying they didn't want you around?

19.*Date (age $12+$ ) At any time in your life, did a boyfriend or girlfriend or anyone you went on a date with slap or hit you?

JVQ Module: Sexual Victimization items used in sexual victimization composites, 'denotes contact sexual

20.'Sex adult (all ages) At any time in your life, did a grown-up ... touch your private parts when they SHOULDN'T have, or MAKE you touch their private parts or did a grown-up FORCE you to have sex?

21.'Sex child (all ages) Now think about other young people, like from school, a friend, or even a brother or sister. At any time in your life, did another child or teenager MAKE you do sexual things?

22.'Try sex (all ages) At any time in your life, did anyone TRY to force you to have sex, that is sexual intercourse of any 
23. Flash (age 2+)

24.Say sex (age 2+)

25. 'Under 16 sex adult (age 12+)

26.'Position of trust

(age 16 \& 17)

kind, even if it didn't happen?

At any time in your life, did anyone make you look at their private parts by using force or surprise, or by "flashing" you?

At any time in your life, did anyone hurt your feelings by saying or writing something sexual about you or your body?

At any time in your life, did you do sexual things with anyone 18 or older, even things you wanted?

Since you were 16, have you done sexual things with anyone who was in a position of trust, such as a teacher or personal adviser, even things you both wanted?

JVQ Module: Witnessing Victimization at Home and Community. Items marked +denote items used in composite for domestic and family violence; \#community victimization exposure

27.+Witness parent (all At any time in your life, did you SEE your parent get pushed, slapped, hit, punched, or beaten up ages)

28.Witness sibling (all

ages)

29.\#Witness weapon

attack

by your other parent, or their boyfriend or girlfriend?

At any time in your life, did you SEE your parent hit, beat up, kick, or physically hurt your brothers or sisters, not including smacking?

At any time in your life, in real life, did you SEE anyone get attacked or hit on purpose WITH a stick, rock, gun, knife, or other thing that would hurt?

30.\#Witnessed unarmed At any time in your life, in real life, did you SEE anyone get attacked or hit on purpose WITHOUT attack using an object or weapon?

31.\#Witness burglary At any time in your life, did anyone steal something from your house that belonged to your family or someone you lived with? Things like a TV, stereo, car, or anything else?

JVQ Module: Exposure to Family Violence and Abuse (supplemental)

32.+Parent threatened

(all ages)

33.+Parent breaks things

(all ages)

34.+Parent physical

35.Witness other family

violence (all ages) violence (all ages)

At any time in your life, did one of your parents threaten to hurt your other parent and it seemed they might really get hurt?

At any time in your life, did one of your parents, because of an argument... break or ruin anything belonging to your other parent, punch the wall, or throw something?

At any time in your life, did one of your parents get kicked, choked, or beaten up by your other parent?

Now we want to ask you about any fights between any grown-ups and teenagers, other than between your parents. At any time in your life, did any grown-up or teenager who lived with you push, hit, or beat up someone else who lived with you?

Neglect (composite from JVQ and NSPCC 2000 survey age under 18)

Absence of physical care \& Access to health care (JVQ)

Educational Neglect

Supervision and monitoring

Respond to emotional needs
36. When someone is neglected, it means that the grown-ups in their life didn't take care of them the way they should. They might not get them enough food, take them to the doctor when they are ill, or make sure they have a safe place to stay. At any time in your life, were you neglected?

37. At any time in your life, did you have to go to school in clothes that were torn, dirty or did not fit because there were no other ones available? [IF AGE> 5]

How does your child do in school? Would you say that (he/she) gets mostly below average grades, pretty much average grades or mostly above average grades?[IF child is getting below average grades] How often, if at all, do you help your child with (his/her) homework?

Your child plays outside without being watched or checked on by an adult? [IF AGE $<5]$

Your child is left alone in a car while you go into a shop, bank, or post office? [IF AGE $<5$ ]

When you go out on your own or with friends of your age, how often do your parents ask you [IF $\mathrm{AGE}<16]$

o who you are going out with

o where you are going or what you are going to be doing?

You encouraged your child to talk about his/her troubles? [if age 10+]

You gave praise when your child was good? [if age 10+]

You joked and played with your child? [if age 10+]

You gave comfort and understanding when your child was upset? [if age 10+]

You told your child that you appreciate what he/she tried or accomplished? [if age 2+]

You expressed affection by hugging or holding your child? [if age 2+]

My family really tries to help me [if age 10+]

My family lets me know that they care about me [if age 10+] 
I can talk about my problems with my family [if age 10+]

My family is willing to help me make decisions [if age 10+]

\begin{tabular}{|c|c|}
\hline \multicolumn{2}{|c|}{ Neglect (composite from items in NSPCC 2000 survey, age 18-24) } \\
\hline & $\begin{array}{l}\text { Parents have different ideas about when a child should be independent } \\
\text { and able to look after themselves. When you were a young child (say } \\
\text { under 12), did you have any of the following experiences? } \\
\text { - Your parents/carers expected you to do your own laundry (under the age of 12) } \\
\text { - You had regular dental check ups } \\
\text { - You went to school in clothes that were dirty, torn, or that didn't fit, because there were no } \\
\text { - } \quad \text { Youn ones available } \\
\text { - You looked after younger brothers or sisters while your parents were out } \\
\text { - You were ill but no-one looked after you or took you to the doctor } \\
\text { - You did not have a safe place to stay }\end{array}$ \\
\hline JVQ Supplementary & Cyber victimization \\
\hline 38. INT 1 & $\begin{array}{l}\text { Has anyone ever used the Internet or a mobile phone to bother or harass you or to spread mean } \\
\text { words, pictures or videos about you? }\end{array}$ \\
\hline 39. INT 2 & try to get you to talk about sex when you did not want to talk about those things? Comment [B1]: \\
\hline \multicolumn{2}{|c|}{ Questions used for polyvictimization composites by age } \\
\hline Children aged under 2 years & $4-10,12,13,15,21,22,27-36$ \\
\hline Ages 2 to 4 years & $1-18,20-24,27-36$ \\
\hline Children aged 5 years & $1-18,20-24,27-36,38 \& 39$ \\
\hline Ages 6 to 11 years & $1-18,20-24,27-39$ \\
\hline Ages 12 to 15 years & $1-25,27-39$ \\
\hline Ages 16 to 17 years & $1-39$ \\
\hline Ages 18+ & 1-36, $38 \& 39$ \\
\hline
\end{tabular}


